\title{
Evaluation of AIDS-Related Disability in a General Hospital in Southern, Brazil
}

\author{
Marise Bueno Zonta1, Sérgio Monteiro de Almeida ${ }^{1}$, \\ Mirian T Matsuno de Carvalho ${ }^{2}$ and Lineu César Werneck ${ }^{1}$
}

\author{
Neurology Division ${ }^{1}$, Infectious Diseases Division ${ }^{1}$, \\ Clinical Hospital, Federal University of Paraná; \\ Curitiba, PR, Brazil
}

\begin{abstract}
The increase in survival rates of patients affected by AIDS is associated with physical disabilities that can compromise their functional independence. We examined the degree and types of disabilities in hospitalized AIDS patients, as well the clinical and immunological parameters associated with disability. The lowered functional status was associated with increased time since AIDS had been diagnosed, with complaints of weakness, and with the involvement of more than one set of systems in the definition of AIDS. The inability to perform daily living activities was associated with higher viral loads $(\log ) \mathrm{c} / \mathrm{mL}$, lower $\mathrm{CD}_{4}^{+} / \mathrm{mL}$ and $\mathrm{CD}_{4}^{+} / \mathrm{CD}_{8}^{+}$ratios, and with involvement of the central nervous system, in the cause of hospitalization. Both the inability to perform daily living activities and low functional status were associated with muscle strength alteration and with being unemployed.

Key Words: AIDS, HIV, disability, functional status, functional assessment, functional independence measure.
\end{abstract}

The treatment of HIV infected patients in Brazil has been a great challenge for health professionals. Latin America holds third place in the epidemic of Acquired Immunodeficiency Syndrome (AIDS) [1], and Brazil is the country with the largest number of infected people, with nearly 600,000 infected individuals. By December 2002, 257,780 AIDS cases had been reported to the Health Ministry, with 185,061 males and 72,719 females [2].

Treatment has led to an increase in life expectancy in the patients who, in turn, have had to deal with a large number of complications and with physical disabilities resulting from infection [3,4]. When their functional abilities are limited, both their independence as well as their quality of life will be compromised [3].

Received on 12 June; revised 08 November 2005.

Address for correspondence: Dr.Marise Bueno Zonta Hospital de Clínicas - UFPR, Neurology Department Rua General Carneiro, 181 Sala 1238. Zip code 80060 -800 Curitiba,PR - Brazil.E-mail: marise.zonta@terra.com.br.Phone/ fax: 55(41) 264-3606. Home phone: 55(41) 242-3024

The Brazilian Journal of Infectious Diseases 2005;9(6):479-488 (C) 2005 by The Brazilian Journal of Infectious Diseases and Contexto Publishing. All rights reserved.
As the number of persons diagnosed with AIDS, as well as their life expectancy, rises, the assessment and treatment of the physical disabilities related to this disease have become increasingly important priorities $[18,19]$. The ability of HIV to involve multiple organ systems, especially the central nervous system, results in a great variety of disabling conditions that can manifest themselves at any time and through different factors associated with the evolution of the disease [2022].

The effects of AIDS disease are not limited exclusively to a biological sphere. Social, political and economic factors are extremely important; treatment and an extended life expectancy of an AIDS patient depend, to a great extent, on the country in which he or she lives.

In a developing country, the need for assistance caused by the reduction of the functional ability of debilitated individuals places a considerable weight on the shoulders of society. In this functional context, assessment is necessary both for clinical research as well as for the definition of the kinds of services required. The knowledge of the normal progression of the disease through its course and the patterns of 
transition in functional status can help in planning rehabilitation [5].

As the impaired ability to perform self-care tasks is the major determinant of need for formal or informal personal care services or other long-term care [6], it is very important for this assessment to take into account the degree of independence for daily-living activities [7]. On the other hand, scales that measure overall independence can provide a gross indication of the functional status and the burden of care [8].

We examined and quantified the various types of physical disability in hospitalized persons affected by AIDS, and we examined associations of disability with immunological and clinical data.

\section{Material and Methods}

\section{Study population}

The study population consisted of 120 inpatients admitted to the Federal University Hospital of Paraná, Brazil, in the city of Curitiba. They were under the care of the Infectious Disease, General and Neurological Clinics. All evaluations were performed by one of the authors (ZMB) in the period from May/2000 to July/ 2001, and each patient was examined once. All patients had proven HIV infection, and all met the Center for Disease Control's criteria for the diagnosis of AIDS [9]. All the patients invited to participate in this study gave their informed written consent.

\section{Evaluation procedure}

The evaluation consisted of an interview with the patient, administration of standard functional assessment instruments, a specific physical exam and retrospective examination of hospital records. During the interview, the patients were questioned about any kind of motor disability, when it started and what other factors could be related to it. They were asked to describe the degree of difficulty they had in the performance of daily activities and at their jobs. We measured functional independence by using the
Functional Independence Measure* (FIM) [10] in 85 patients and the Barthel Index [11,12] in 120 patients. Evaluation was completed by actual patient observation or by simulation of the functional activity. To measure the functional status of the 120 patients, we used the modified Rankin score [13] and the Karnofsky Performance Status $[14,15]$. Consulting with the patients' primary nurse or caregivers was also used and was especially helpful in completing the social cognition assessment. The physical exam consisted of measuring muscular strength in muscular groups or specific muscles (upper limbs: deltoid, biceps, triceps and palmar flexors; lower limbs: hip flexors, quadriceps, hamstrings and dorsal flexors). Strength was measured from 0 (absence of muscular contraction) to 5 (normal active movement) [16].

An examination of the hospital records provided the clinical and immunological data, including viral load (log) $\mathrm{c} / \mathrm{mL}, \mathrm{CD}_{4}^{+} / \mu \mathrm{L}$ counts and $\mathrm{CD}_{4}^{+} / \mathrm{CD}_{8}^{+}[17]$; medical history, data on the AIDS-defining illness, admission cause, risk factors for HIV infection and neurological involvement.

\section{$\underline{\text { Statistical approach }}$}

The patients were separated into two groups for the evaluation of the results of the Karnofsky scale and their correlations: up to $70 \%$ (dependent or partially dependent), and above $70 \%$ (independent). For analysis by the modified Rankin Score, the degrees of independence ( 0 and 1) were grouped, the same being done for the other group - 2 to 5 (dependent or partially dependent). Two groups were indicated for each specific item of the Barthel Index: one for independence and another for dependence and need of assistance. For the evaluation of the FIM scale, the independent (scores 6 and 7) and the dependent or partially dependent classifications were grouped (scores 1 to 5) for each item.

The Student-t test was used to compare quantitative variables of the two groups. The non-parametric MannWhitney test was adopted for the variable log viral load,. For the qualitative variables, Fisher's Exact Test was adopted. A 0.05 significance level was adopted for all the tests. 


\section{Results}

$\underline{\text { Patient demographics }}$

Among the 120 patients evaluated in this study, $65 \%$ were male, $89 \%$ were white, $8 \%$ were black and $3 \%$ mixed, 39\% were intravenous drug addicts and $62 \%$ reported contracting the disease through sexual contact. There was more than one risk factor involved in $17 \%$ of the patients, and in $36 \%$ there was no information in the records about the transmission of the virus.

The average age was 35 years $(\mathrm{SD}=8.5)$, median of 34 , varying from 20 to 57 years. Average duration of schooling was 6 years $(\mathrm{SD}=3.3)$, median of 6 , range $0-15$ years; there was no information on this item for 28 patients.

Regarding the cause of admission, $52 \%$ of the patients had pulmonary disease; $44 \%$ had gastrointestinal disease, $35 \%$ had neurological complications, $20 \%$ had a blood deficiency, $12 \%$ had genitourinary disease, $10 \%$ mucocutaneous disease, $5 \%$ visual and vestibular disease, $2 \%$ cardiovascular disease, and 32\% had systemic involvements. Among the 120 patients evaluated in our study, $72 \%$ had more than one set of systems involved as the cause of admission and $12(10 \%)$ were admitted with exclusively neurological complications.

Regarding the AIDS-defining illness, $43 \%$ were related to pulmonary disease, $29 \%$ to a blood deficiency, of whom $16 \%$ had only immunosuppression characteristics, $28 \%$ had neurological complications, $23 \%$ gastrointestinal disease, $9 \%$ systemic involvement, $5 \%$ mucocutaneous disease, $3 \%$ visual and vestibular disease, $3 \%$ genitourinary disease and $1 \%$ cardiovascular disease. Among the 120 patients, 29\% had an AIDSdefining illness with the involvement of more than one set of systems and $21 \%$ exclusively with neurological complications, 29\% had their AIDS-defining illness during this hospitalization. The data on clinical and immunological assessment are shown in Table 1.

Among the 120 patients, $67 \%$ were not employed, and $52(43 \%)$ had quit their jobs for infection-related reasons. Among the 52 who left their jobs, $44 \%$ mentioned weakness as the main cause that prevented them from maintaining their jobs.
Disability

Among the 120 patients, $85 \%$ reported impaired physical activity. Seventy percent of the patients complained about various degrees of weakness. When questioned about the type of weakness, $50 \%$ stated that they performed all of their regular activities, although at a slower pace, with pauses for resting; $42 \%$ admitted that they had difficulty making larger efforts and $8 \%$ felt like lying in bed. Besides weakness, other complaints were related to impaired physical activity (Figure 1).

Fifty-five (45\%) of the patients reported disability related to neurological complications, which included: paresthesis in $44 \%$ of patients, headache in $22 \%$, dizziness in $16 \%$, balance impairment in $13 \%$, convulsions in $11 \%$, disorientation in $7 \%$ and mental confusion in $7 \%$.

Muscular strength was altered in 52\% of patients; among them, $68 \%$ reported weakness and $56 \%$ had complaints about disabling neurological involvement. The cause of admission was considered to be neurological complications in $34 \%$, respiratory disease in $31 \%$, gastrointestinal disease in $24 \%$, wasting syndrome in $13 \%$, and other reasons in $6 \%$. Among the patients who had their muscular strength altered, $79 \%$ were unemployed when admitted.

Functional assessment and correlates of AIDS-caused disability

Hypothesized associations with disability included age, gender and race, time elapsed since the HIV diagnosis, time elapsed since the AIDS diagnosis, log viral load in c/mL, $\mathrm{CD}_{4}{ }^{+}$counts, $\mathrm{CD}_{4} / \mathrm{CD}_{8}$ ratios, involvement of more than one set of systems in the AIDS-defining illness, involvement of the central nervous system in the cause for admission, muscle strength alteration and employment.

The Karnofsky scale ( $\mathrm{n}=120)$

Based on this classification, $52 \%$ of the patients had normal activity with effort (score 80\%). The mean situation of the patients was a score equivalent to caring 
Table 1. Clinical and immunological characteristics of the assessment of AIDS patients

\begin{tabular}{lcccc}
\hline & Mean & Median & SD & N \\
\hline Duration of HIV diagnosis (months) & 36.90 & 24 & 41.40 & 120 \\
Time since AIDS diagnosis (months) & 11.60 & 1 & 19,70 & 120 \\
Viral Load c/mL* & 335.65 & 140.00 & 491.77 & 34 \\
$\mathrm{CD}_{4}^{+} / \mu \mathrm{L}$ & 74.57 & 51 & 84.90 & 119 \\
$\mathrm{CD}_{8}^{+} / \mu \mathrm{L}$ & 493.00 & 412 & $458 ; 70$ & 101 \\
$\mathrm{CD}_{4}^{+} / \mathrm{CD}_{8}^{+}$ & 0.20 & 0.1 & 0.31 & 102 \\
\hline
\end{tabular}

$\mathrm{SD}=$ Standard deviation. $*$ Viral load in the last three months.

Table 2. Disability frequency in AIDS patients

\begin{tabular}{llr}
\hline Item & \multicolumn{2}{c}{ Number Needing Human Assistance } \\
\cline { 2 - 3 } & N & \% \\
\hline Eating & 18 & 21 \\
Grooming & 17 & 20 \\
Bathing & 20 & 24 \\
Dressing - Upper body & 19 & 22 \\
Dressing - Lower body & 21 & 25 \\
Toileting & 16 & 19 \\
Bowel management & 13 & 15 \\
Bladder management & 17 & 20 \\
Transfers: bed, chair, wheelchair & 19 & 22 \\
Transfers: toilet & 19 & 22 \\
Transfers: tub or shower & 20 & 24 \\
Walk/wheelchair & 24 & 28 \\
Stairs & 31 & 36 \\
Comprehension & 11 & 13 \\
Expression & 11 & 13 \\
Social interaction & 11 & 13 \\
Problem Solving & 11 & 13 \\
Memory & 11 & 13 \\
\hline
\end{tabular}


for self, being unable to perform normal activities or an active job (score $70 \% \pm 0.19$ ), with a median of $80 \%$, varying from $10 \%$ to $90 \%$. There was an association between a lower functional status with alteration in muscular strength $(\mathrm{p}<0.0001)$, as well as with being unemployed $(\mathrm{p}=0.01)$.

\section{The rankin modified scale $(\mathrm{n}=120)$}

There was an association between lower functional status and the length of time elapsed since AIDS was diagnosed (Figure 2), with the involvement of more than one set of systems and the AIDS-defining illness $(\mathrm{p}=0.01)$, and with muscular strength alteration $(\mathrm{p}=$ $0.001)$ and with being unemployed $(\mathrm{p}=0.009)$.

\section{The Barthel index $(n=120)$}

Among the 120 patients, $56 \%$ were considered independent (score100 BI), 34\% were considered partially dependent (score between 50 and 100), and $10 \%$ were considered dependent (score lower than $50 \mathrm{BI}$ ). The activities requiring moderate or greater assistance were walking, ascending or descending stairs and transfers.

There was an association between the inability to perform the following actions: getting dressed $(\mathrm{p}=$ $0.01)$, getting on and off a toilet $(\mathrm{p}=0.1)$ and bathing $(p=0.04)$, and high log viral load. There was an association between the inability to ascend and descend stairs $(\mathrm{p}=0.05)$ and lower $\mathrm{CD}_{4}^{+}$counts, even though they were lower than the what is considered normal, they were higher in those considered as being independent. There was an association between the inability to use the toilet $(\mathrm{p}=0.01)$ and lower $\mathrm{CD}_{4}^{+} /$ $\mathrm{CD}_{8}^{+}$ratios. There was an association between the inability to perform the following: feeding oneself $(\mathrm{p}=$ $0.008)$, use of toilet $(\mathrm{p}=0.03)$, controlling bowels $(\mathrm{p}=$ $0.03)$, getting dressed $(\mathrm{p}=0.02)$, and getting on and off the toilet $(p=0.04)$, and the involvement of one or more sets of systems in the cause for admission. There was an association between muscular strength alteration and the inability to do the following: controlling the bladder $(\mathrm{p}=0.01)$, getting dressed $(\mathrm{p}=0.002)$, moving from wheelchair to bed $(\mathrm{p}=<0.0001)$, walking $(\mathrm{p}=$ $<0.0001)$, ascending and descending stairs $(\mathrm{p}=0.0001)$ and bathing $(\mathrm{p}=0.003)$. There was an association with the inability to move from wheelchair $(p=0.04)$ and walking $(\mathrm{p}=0.04)$ and a complaint about more significant degrees of weakness. There was an association with the inability to perform the following: feeding oneself $(\mathrm{p}=0.04)$, controlling bowel movements $(\mathrm{p}=0.006)$, controlling bladder $(\mathrm{p}=0.003)$, getting dressed $(\mathrm{p}=0.02)$, getting on and off the toilet $(\mathrm{p}=$ $0.02)$, ascending and descending stairs $(p=0.04)$, with the fact of being unemployed.

\section{$\underline{\text { FIM }^{*}(\mathrm{n}=85)}$}

Among the 85 patients evaluated with the FIM instrument, 36 (42\%) were dependent, requiring human assistance in at least one item of the scale, and $22(26 \%)$ required assistance in four or more areas.

The frequency of the occurrence of specific disabilities as measured by the FIM, is summarized in Table 2. There was an association between the inability to control the bladder $(\mathrm{p}=0.01)$ and a higher mean log viral load. The items bathing $(\mathrm{p}=0.06)$, grooming $(\mathrm{p}=$ $0.06)$, transfers from bed to wheelchair $(\mathrm{p}=0.06)$ and to toilet $(p=0.06)$ had values that were very close to significant. There was an association between the inability to perform the following: comprehension $(\mathrm{p}=$ $0.03)$, expression $(\mathrm{p}=0.03)$, social interaction $(\mathrm{p}=$ $0.03)$, problem solving $(\mathrm{p}=0.03)$ and lower $\mathrm{CD}_{4}^{+} /$ $\mathrm{CD}_{8}^{+}$ratios. There was also an association between inability and the involvement of the central nervous system in the cause for admission (Figure 3 ). There was an association between the inability to perform the following: grooming $(p=0.04)$, bathing $(p=0.003)$ dressing - lower body $(\mathrm{p}=0.003)$, using the toilet $(\mathrm{p}=$ $0.003)$, bladder management $(\mathrm{p}=0.003)$, transfers to and from bed, chair, wheelchair $(\mathrm{p}=0.01)$, ascending and descending stairs $(\mathrm{p}=0.001)$ and alteration in muscular strength. There was likewise an association between the inability to do the following: dressing upper body $(p=0.03)$ and lower body $(p=0.01)$; toileting $(p=0.01)$, bladder management $(p=0.009)$, transferring to and from bed, chair, wheelchair $(\mathrm{p}=$ 
Figure 1. Complaints related to impaired physical activity in AIDS patients.

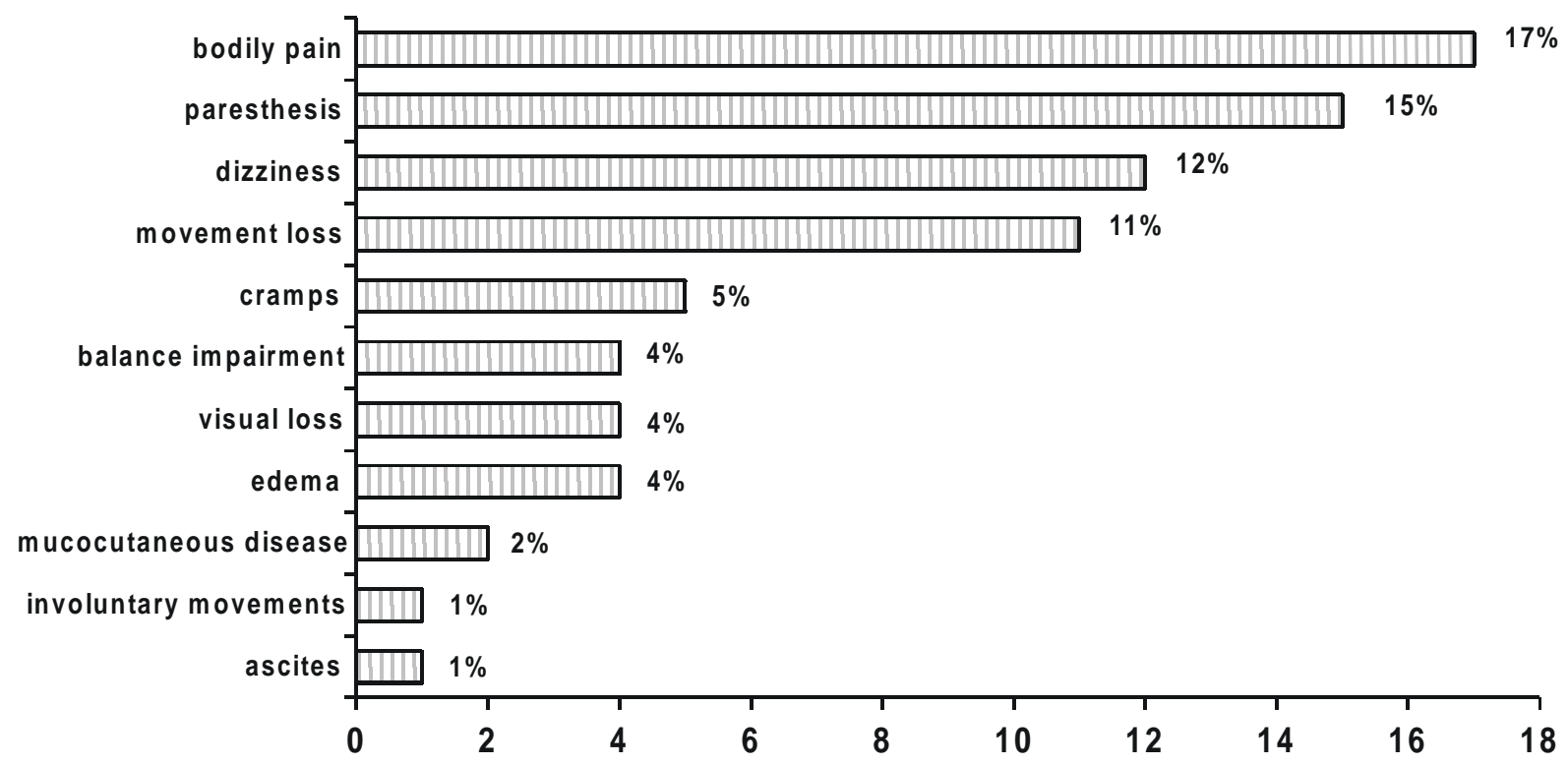

Figure 2. Association between lower functional status and the length of time elapsed since AIDS was diagnosed $(\mathrm{p}=0.0005)$.

TIME OF DISEASE

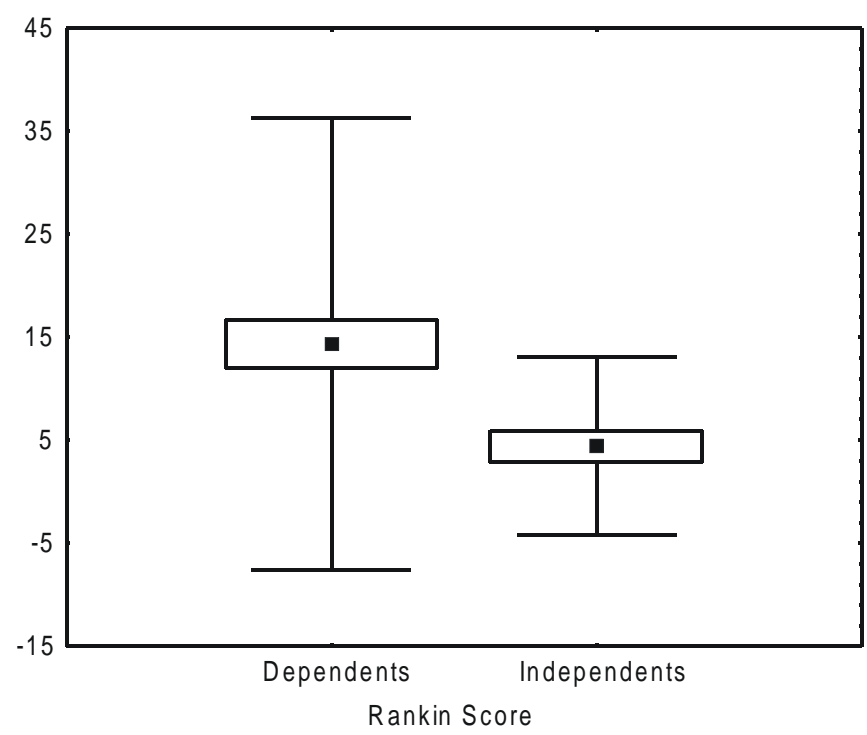

I \pm Standard Deviation

$\square \pm$ Standard Error

- Mean 
Figure 3. Association between disability with the involvement of the central nervous system in the cause for admission.

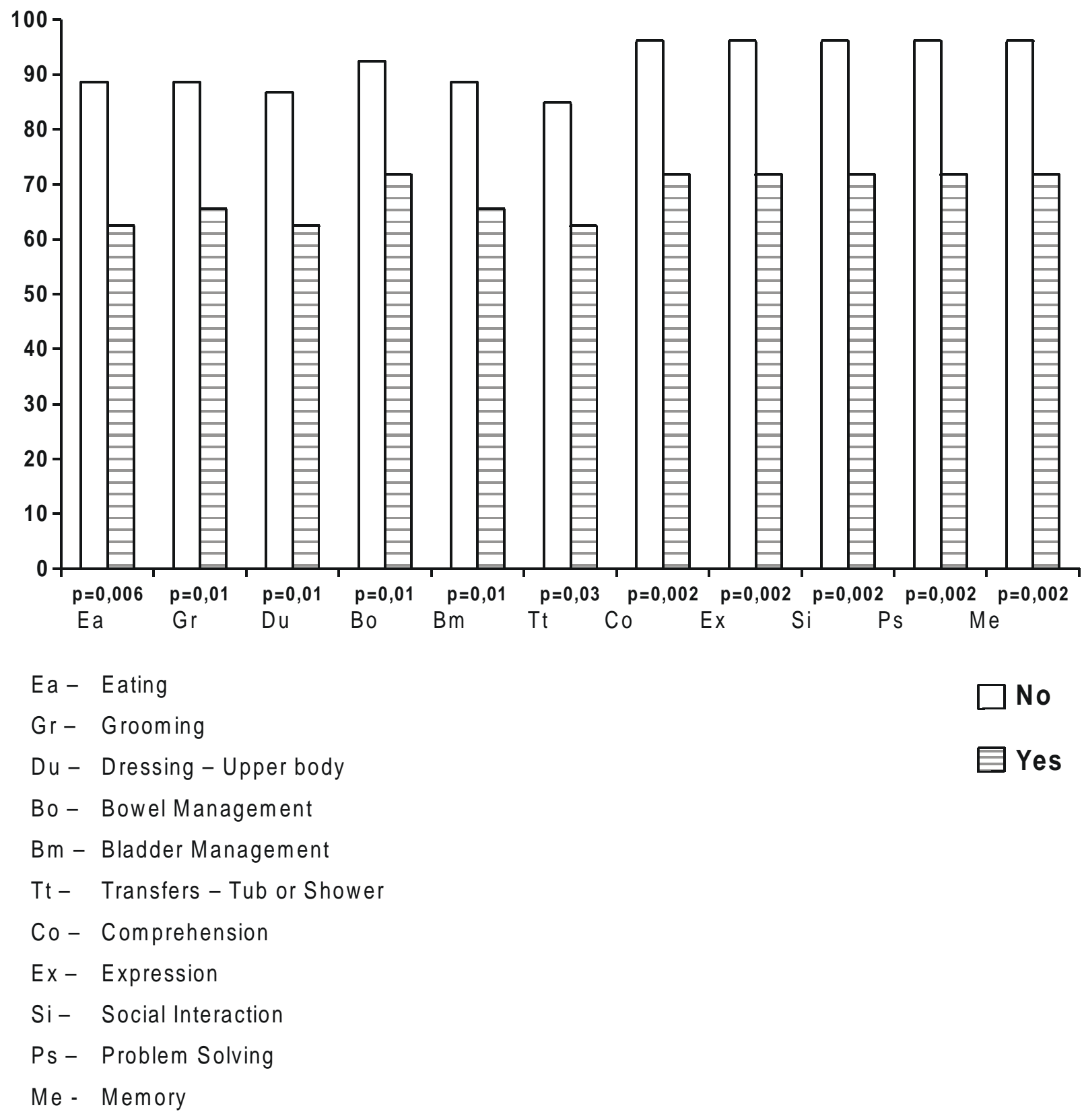


$0.003)$, transferring to and from toilet and to and from tub or shower (0.03) and the fact of being unemployed. Seven other items showed values that were very close to significant.

\section{Discussion}

One of the ways to observe the consequences of infection by HIV is through an evaluation of the functional ability of the patients [5]. We found a significant incidence of disabilities in an AIDS-affected population, with $85 \%$ of the patients complaining of impaired physical activity, and $82 \%$ reporting different degrees of weakness.

The Karnofsky scale, although it did not provide detailed information on physical disability, showed that the need for effort to perform day-to-day activities compromised the independence and the quality of life of half of this population.

The modified Rankin scale [23] provided an even broader view of overall independence, which made it possible to associate the variables duration of disease and involvement of one or more systems in the AIDS picture.

The variety and quantity of motor deficits noted in this study through the evaluation by means of the FIM scale can be compared with a study [7] based on 37 discharge evaluations where the FIM scale was used. In both studies the items most often requiring human assistance were stair climbing and ambulation, as they are the items that require the greatest physical effort and balance.

The data of our study are based on a single evaluation, and the severity and frequency of the disabilities would probably be much greater if they were longitudinally assessed. Even so, high levels of disability were observed in the population, which raises several questions regarding the assessment of the disability, as well as with respect to the possible interventions in terms of rehabilitation $[32,33]$.

\footnotetext{
* With permission of the Research Committee of Uniform Data
} System for Medical Rehabilitation.
Consistent with previous studies [3], no significant differences were found as regards age, sex and race in any of the four scales that were used. Neither did this study reveal any associations between inability and the time elapsed since infection by HIV.

In this sample, $29 \%$ of the patients were diagnosed with AIDS upon admission; this can partly explain the lower levels of inability and the lack of relationship with infection by HIV. Based on a study [3] which evaluated 391 individuals having AIDS by means of the AIDS Time-oriented Health Outcome Study (ATHOS), severe disability was relatively unusual, while mild and moderate disability were more common, as we also noted in our study.

A significant association between the functional status and the time elapsed since AIDS diagnosis $(\mathrm{p}=0.0005)$ was expected. As the immune compromise advances, patients will gradually lose their ability to recover functionally [7].

Even though we had few results on this factor, there was an association between lower functional status and higher average viral $\operatorname{load}(\log \mathrm{c} / \mathrm{mL})$, which suggests a greater compromise brought about by the disease.

In a cohort study [24], which kept track of the progression to AIDS for three years, there was a strong association between progression and lower $\mathrm{CD}_{4}^{+}$ counts. Both the the lymphocyte counts and the $\mathrm{CD}_{4}^{+}$/ $\mathrm{CD}_{8}^{+}$ratio allow for an evaluation of the patient's cellular immunity compromise, and both were associated in this study.

Disorders affecting the central nervous system are among the most common causes of disability in patients with AIDS [25-27]. In our study, the association of inability with the involvement of the nervous system in the cause of admission was observed by using two scales. The social cognition and communication items were the most significant ones, which suggests that the application of the FIM scale may be indicated for patients with AIDS, due to the possibility of a minimal cognitive-motor disturbance being present, in addition to demential conditions that might be suggested by this evaluation.

Both the functional status and the disability evaluations were associated with alterations in muscular strength. This alteration, which was present in $43 \%$ of the 
population, accompanied complaints about neurological involvement, weakness and a worsening of the overall status. Another study [28] mentioned that both the neurological and the constitutional symptoms were highly significantly correlated with physical function. Fatigue contributes to morbidity and inability, mainly in stage IV of the CDC classification, which corresponds to the AIDS-related complex and to AIDS itself [29], which was the diagnosis of the patients in our study.

Consistent with other studies, the work variable was also associated with disability [30] and with low functional status. The ability to work may involve the social function, but it mainly involves the physical function, ability that generally implies the prerequisites of mobility and self-care. Many AIDS factors may determine the need to give up one's job, and many AIDS patients mention fatigue as the main reason why they gave up their professional activities [19,29].

In our study, several reasons related to systemic complications and resulting from HIV infection caused 52 patients to give up their jobs. Among them, weakness was mentioned by $44 \%$ of these patients, but other factors such as incapacitating edemas, skin lesions, loss of sight, as well as prejudice, both on the part of the patient and of society, contributed to their giving up their jobs. This situation is consistent with the observations of another study [31], which warns about the care that must be taken in the interpretation of the relationship between functional disability and work, as many other factors, besides physical inability, affect the decision to give up one's job.

Due to the great variability of types and severity of the functional deficits, a single scale would rarely be adequate for this type of evaluation. This explains why among the studies that we mentioned, different scales and indices were used for the evaluation of patients with AIDS. The four functional scales used in our study have contributed to the literature related to physical disability resulting from AIDS; first because they show the efficacy of the use of a more simplified scale, like the Rankin one, which allows for important and significant relationships; on the other hand, the efficacy of the Karnofsky scale was confirmed, which, despite being generic, classifies the functional status in a more specific manner, as in the case of fatigue and physical effort of AIDS patients.
As far as functional ability is concerned, both scales assess in detail the degree of independence of patients, but in the case of an AIDS-infected population the FIM scale may be more useful, as it includes cognitive and communication items. The FIM scale grades in greater detail the amount of human assistance required by the patient, which would be useful in case it is used for selecting patients for specialized care. The FIM scale also differentiates modified independence, by detailing the need for some type of support. As far as our study is concerned, the most significant contribution has to do with the evaluation of the items of communication and social cognition.

A preventive program would have a greater possibility of significantly contributing to maintaining the patients as productive individuals in society for a longer period of time [18]. Whenever they are indicated, the techniques used in order to prevent disability are not going to alter the progress of the disease, but they often increase the patient's functional status [31].

Considering that, once they are infected by HIV, virtually all patients will be hospitalized at some point due to this disease [34], there is little reason to believe that our sample will be very different from other patients at the same stage of disease. On the other hand, even if they happen to be broadly representative of patients hospitalized with AIDS, it must be remembered that our study was limited to hospitalized patients from in and around the city of Curitiba. Hence, the results may not be generalized, as they do not contemplate outpatients and those who were not hospitalized by reason of infection.

The awareness of problems and subsequent disabilities seen in AIDS are indispensable for proper management, which includes prevention, basic care and rehabilitation services. Timely attention to physical and functional shortcomings is crucial if a better quality of life is to be ensured for these patients.

\section{References}

1. Veronesi R.,Focaccia R., Mazza C.C., Weinberg A. AIDS/SIDA Síndrome de Imunodeficiência Adquirida. In: Machado L.R., Nóbrega J.P.S., Livramento J.Á., Spina A. Editors. Neuroinfecção 94. São Paulo:USP;1994.p.255-68. 
2. Brasil, Ministério da Saúde. Coordenação Nacional de DST E AIDS. Dados e Pesquisas em DST e AIDS. Boletim Informativo (11/25/2002). Available at: www.saude.gov.br.

3. O'Dell M.W. HIV-related neurological disability and prospects for rehabilitation. Disabil Rehabil 1996; $18: 285-92$.

4. O'Dell M.W., Dillon M.E. Rehabilitation in adults with human immunodeficiency virus-related diseases. Am J Phys Med Rehabil 1992;71:183-190.

5. Benjamin AE. Perspectives on a continuum of care for persons with HIV illnesses. Med Care Rev 1989;46:411-37.

6. Crystal S., Sambamoothi U. Functional impairment trajectories among persons with HIV disease: a hierarchical linear models approach. Health Serv Res 1996;31:469-88.

7. O'Dell M.W., Crawford A., Bohi E.S., Bonner F.J. Disability in persons hospitalized with AIDS. Am J Phys Med Rehabil 1991;70:91-5.

8. O'Dell M.W., et al. Inter-rater reliability of the Karnofsky performance status in a HIV-infected sample. AIDS 1991;9:1396-7.

9. Centers for Disease Control. 1993 revised classification system for HIV infection and expanded surveillance case definition for AIDS among adolescents and adults. MMWR 1992;41:1-19.

10. Granger C, Hamilton B; Development of a Uniform National Data System For Medical Rehabilitation 1984-97. Final Report for Grant Number G008435062. Buffalo: National Institute on Disability and Rehabilitation Research, Office of Special Education and Rehabilitative Services, Department of Education, 1987.

11. Mahoney F.I., Barthel D.W. Functional Evaluation: The Barthel Index. Md St Med J Baltimore 1965; 14:61-5.

12. André C. Manual de AVC. Rio de Janeiro, Revinter, 1999. p150-1.

13. Rankin J. Cerebral Vascular Accidents in Patients over the age of 60.2: Prognosis. Scott Med J 1957;2:200-5.

14. Karnofsky D.A., Abelmann W.H., Craver L.V., Burchenal J.H. The use of the nitrogen mustards in the palliative treatment of carcinoma : with particular reference to broncogenic carcinoma. Cancer 1948; 1:634-56.

15. O'Dell M.W., et al. Interrater reliability of the Karnofsky performance status in a HIV-infected sample. AIDS 1991;9:1396-7.

16. Dejong R.N. Motor strength and power. In: The Neurologic Examination. $3^{\text {rd }}$ edition. Harper and Row Publishers; New York: 1967.p.447-96.

17. Lifson J.L., Engleman E.G.. Role of CD4 in normal immunity and HIV infection. Immunol Rev 1989;109:93-117.

18. O'Connell P.G., Levinson S.F. Experience with Rehabilitation in the Acquired Immunodeficiency Syndrome. Am J Phys Med Rehabil 1991;70 195-200.
19. Levinson S.F., O’Connell P.G. Rehabilitation Dimensions of AIDS: a review. Arch Phys Med Rehabil 1991;72:690-6.

20. O'Connell P.G.. AIDS: a Medical rehabilitation perspective. Occup Ther Health Care 1990; 7:19-43.

21. Berger J.R., Simpson D.M. Neurologic Complications of AIDS.In: Infections of the Central Nervous System. Scheld WM, Whitley RJ, Durack DT.. 2 ed Philadelphia: Lippincott-Raven Publishers; 1997. p. 255-67.

22. Rosen L., Strax T.E., Bakst B. HIV and the nervous system: implications for rehabilitation (abstract). Arch Phys Med Rehabil 1988;69:716.

23. Grant A., O'Brian B., Dick D.J. Neuropathy test and normative result. In: Dick, D.J., Thomas P.K., editors. Diabetic neuropathy. 2nd edition. Philadelphia: WB Gandeira; 1999.p.123-41.

24. Pedersen C., et al. The development of AIDS-related conditions in a cohort of HIV antibody-positive homosexual men during a 3-year follow-up period. $\mathrm{J}$ Intern Med 1989;225:403-9.

25. Levinson S.F., Merritt L.M. Disability due to central nervous system impairment. Phys Med Rehabil, State of the Art Reviews, 1993; Special Issue, 7:S101-18.

26. O'Dell M.W., Sasson N.L. Hemiparesis in HIV infection. Rehabilitation Approach. Am J Phys Med Rehabil 1992;71:291-6.

27. Galantino M.L., Levy J.K. HIV Infection. Neurological implications for rehabilitation. Clin Manag 1988;8:6-13.

28. Wachtel T., et al. Quality of life in persons with human immunodeficiency virus infection: measurement by the Medical Outcome Study instrument. Ann Intern Med 1992;116:129-37.

29. Darko D.F., et al. Fatigue, sleep disturbance, disability, and indices of progression of HIV infection. Am J Psychiatr 1992;149:514-20.

30. O'Dell M.W., et al. Pre-AIDS Physical disability: Data from the AIDS-Time-Oriented Health Outcome Study. Arch Phys Med Rehabil 1998;79:1200-5.

31. O'Dell M.W., et al. Physical disability in a cohort of persons with AIDS: data from the AIDS-Time-Oriented Health Outcome Study. AIDS 1996;10:667-73.

33. Furth P.A., Maloof M., Flynn J.P.G. Rehabilitation and AIDS - Primary Care or System. MD Med J 1988;37:469-71.

33. Sliwa J.A., Smith J.C. Neurologic Disability Related to Human Immunodeficiency Virus. Arch Phys Med Reabil 1991;72:759-62.

34. Globe D.R., Hays R.D., Cunningham W.E. Associations of Clinical Parameters with health-related quality of life in hospitalized persons with HIV disease. AIDS Care 1996; 11:71-86. 